\title{
The relationship of interacting immunological components in dengue pathogenesis David G Nielsen
}

\author{
Address: Department of Microbiology and Immunology, Tulane University, (1430 Tulane Avenue) SL-38 (New Orleans) Louisiana (70112-2699) \\ USA \\ Email: David G Nielsen - dnielsen@tulane.edu
}

Published: 27 November 2009

Virology Journal 2009, 6:21I doi:I0.1 I86/I743-422X-6-2II

This article is available from: http://www.virologyj.com/content/6/I/2II

(c) 2009 Nielsen; licensee BioMed Central Ltd.

This is an Open Access article distributed under the terms of the Creative Commons Attribution License (http://creativecommons.org/licenses/by/2.0), which permits unrestricted use, distribution, and reproduction in any medium, provided the original work is properly cited.
Received: 27 October 2009

Accepted: 27 November 2009

\begin{abstract}
The World Health Organization (WHO) estimates that there are over 50 million cases of dengue fever reported annually and approximately 2.5 billion people are at risk. Mild dengue fever presents with headache, fever, rash, myalgia, osteogenic pain, and lethargy. Severe disease can manifest as dengue shock syndrome (DSS) or dengue hemorrhagic fever (DHF). Symptoms of DSS/DHF are leukopenia, low blood volume and pressure encephalitis, cold and sweaty skin, gastrointestinal bleeding, and spontaneous bleeding from gums and nose. Currently, there are no therapeutics available beyond supportive care and untreated complicated dengue fever can have a $50 \%$ mortality rate. According to WHO DSS/DHF is the leading cause of childhood mortality in some Asian countries. Dendritic cells are professional antigen presenting cells that are primary targets in a dengue infection. Dengue binds to Dendritic Cell-Specific Intercellular adhesion molecule-3Grabbing Non-integrin (DC-SIGN). DC-SIGN has a high affinity for ICAM3 which is expressed in activating T-cells. Previous studies have demonstrated an altered T-cell phenotype expressed in dengue infected patients that could be potentially mediated by dengue-infected DCs.

Dengue is enhanced by three interacting components of the immune system. Dengue begins by infecting dendritic cells which in immature dendritic cells is mediated by DC-SIGN. In mature dendritic cells, antibodies can enhance dengue infection via Fc receptors. Downstream of dendritic cells T-cells become activated and generate the very cytokines implicated in vascular leak and shock in addition to activating effector cells. Both the virus and the antibodies are involved in release of complement and anaphylatoxins which can cause or exacerbate DHF/DSS. These systems are inextricable and strongly associated with dengue pathogenesis.
\end{abstract}

\section{Dengue Background and Significance}

The Dengue Virus is a member of the family Flaviviridae along with other noted viruses Yellow Fever, West Nile, and Japanese Encephalitis. Dengue is a positive stranded RNA arbovirus transmitted by mosquitoes typically Aedes aegypti. Dengue fever has spread from the border lands of Texas to South and Central America, from Africa to the Middle East to Indonesia and Australia. The World Health
Organization (WHO) estimates between 50 million and 100 million infections every year all over the world[1]. Dengue fever will often present with fever, rash, headache, and myalgia but can also develop into much more serious cases of Dengue Hemorrhagic Fever and Dengue Shock Syndrome (DHF/DSS). Cases of DHF/DSS are increasing rapidly as the virus increases in geographic range, with approximately $25-37 \%$ of symptomatic cases of dengue 
requiring hospitalization [2]. Case fatality rates for Dengue can be as high as $40-50 \%$ in untreated patients $[3,4]$. The dengue virus has a significant impact on the health of those it infects and represents a burdensome cost to the patient and health infrastructure in places that can ill afford new and varied threats. Patients who acquire the disease the first time (primary infections) are often asymptomatic and will generate immunity to homologous strains of the virus; however, ninety percent of DHF/ DSS cases come from a second exposure (secondary infection) to a heterologus strain of dengue[5]. Patients with a secondary heterotypic infection are at least 40-80 times more likely to develop DHF/DSS as patients with a primary infection[6]. The mechanisms by which dengue would cause severe disease are currently being elucidated, but the prevailing literature suggests three interacting components necessary for dengue induced immune enhancement. One component is misregulation of cell mediated immunity. In this context, the cross relationship between $\mathrm{B}$ cells and $\mathrm{T}$ cells begins with dengue infection of dendritic cells that, in turn, promiscuously activates $\mathrm{T}$ cells. T cells during a dengue infection have prolific and cross reactive effector functions in addition to producing copious amounts of cytokines that feature prominently in cases of DHF/DSS. A second component in immune enhancement is Antibody Dependant Enhancement (ADE). Heterologus non-neutralizing antibodies recognize dengue epitopes and enhance infectivity in an Fc dependant manner. Further, antibodies have been implicated in an autoimmune disease which can also exacerbate vascular leak and cytokine production. A third interacting component in immune activation is complement. Many of the key cytokines implicated in the cytokine storm that characterizes DHF/DSS are regulated by Complement proteins and associated anaphylatoxins. These three systems both interact and reinforce each other to create a potentially life threatening situation during a Dengue infection.

\section{Antibodies}

Antibody Dependent Enhancement (ADE) has been proposed to be a mechanism by which the immune system may enhance viral pathogenesis[7]. When monkeys were passively immunized concurrently with a viral infection they developed 15 fold higher viral titers than monkeys infected without IgG supplement[8]. However, our understanding of this disease is severely limited by appropriate animal models. Animal models can support viral propagation, but do not exhibit illness unless severely immunocompromised. Epidemiological evidence in Hawaii, Cuba, and Thailand[9] shows populations with previous exposure to the dengue virus are at an increased risk for DHF/DSS. Also infants born to dengue immune mothers were shown to be at an increased risk for DHF/DSS[10]. It's not clear how antibodies enhance viral infection. One hypothesis suggests that non-neutralizing antibodies direct active virions to permissive cells in the immune system[11]. There is no "classical" enhancing antibody since all antibodies will enhance the virus at non-neutralizing concentrations[12]. The Fc receptor (FcR) family is a key component in the ADE pathogenesis model. Fc receptors are found on most phagocytes including dendritic cells and macrophages. The FcR functions as a multisubunit complex that typically binds to $\operatorname{IgG}$ and is composed of an $\alpha$ chain for domain recognition, an ITAM (immunoreceptor tyrosine based activation motif), and a $\gamma$ chain that is responsible for signal transduction. It is thought that IgM does not play a direct role in ADE and instead contributes to disease pathogenesis through activation of complement receptors[13]. IgM antibody enhancement was abrogated when C3R is blocked[14]. A hypothesis suggesting that both IgG and IgM mediate viral enhancement implies that the mechanism for ADE is multivariable. FcR signaling pathways generally leads to activation of the immune cell, though under certain circumstances FcR can lead to immune modulation[15]. The normal interaction of virus with antibody generally leads to neutralization. However, in heterotypic dengue virus infections the antibodies are non-neutralizing and lead to enhancement. Two cell lines expressing either FcyRIA or Fc $\gamma$ RIIA have been used to demonstrate that immune complexes can enhance virus infectivity in an FCR mediated fashion. FcyRIA is found exclusively on macrophages and dendritic cells and preferentially binds monomeric IgG, while Fc $\gamma$ RIIA is more broadly distributed and preferentially binds immune complexes. When exposed to the immune complexes containing the virus, both cell lines showed enhanced infectivity. However, when the signaling capacity of the Fc Receptor was abrogated, phagocytosis is reduced but enhancement is not affected in Fc $\gamma$ RIIA. In the FcyRIA cell line, both the phagocytosis and the immune enhancement are reduced with abrogated cell signaling. The disparity is not yet understood. It does suggest that viral entry and immune enhancement can be mediated by more than a single mechanism. In a different study, three cell types have been used to demonstrate enhancement[16]. U9357 cells which express both FcyRIIA and FcrRI have similar antibody-dependent enhancement capabilities as K562 cells that express just FcyRII. However, the cell type Raji-1 which displays DC-SIGN instead of the Fc receptor showed high viral titers but no antibody enhancement.

\section{Dendritic Cells}

The putative receptor and initial target cell for the virus is DC-SIGN (Dendritic Cell-Specific Intercellular adhesion molecule-3 (ICAM3)-Grabbing Non-integrin) (CD209) on dendritic cells [17-19]. Dendritic cells are considered crucial to fighting viral infections because of their ability to acquire and display viral antigens that would otherwise 
evade the immune system. Dendritic cells affect the dengue virus in two ways. Immature dendritic cells express high levels of DC-SIGN which facilitates initial viral binding and entry. While mature dendritic cells do not posses high levels of DC-SIGN, they do facilitate ADE via Fc $\gamma$ IIa and FcyIIb receptors. This effect was most prominent with serum dilutions ranging from 1:640 to 1:2,560 with complete neutralization at 1:10. ADE in dendritic cells can increase viral RNA production by over 100-fold making dendritic cells potent components in dengue pathogenesis[20]. Infected dendritic cells also contribute to vascular leak through the production of matrix metalloproteinases (MMPs). MMP-2, MMP-13, and MMP-9 were all dramatically increased in immature dendritic cells infected with DENV2. As a result cell-cell adhesion in cells co-cultured with infected dendritic cells was reduced, there were changes in cell morphology and actin cytoskeleton, and a decrease in PECAM 1 VE-cadherin expression[21].

DC-SIGN has a high affinity to the ICAM3 molecules expressed on T-cells with a complicated system of cross talk that can lead to a variety of outcomes[22]. To become activated, T-cells go through a time consuming and multiphase process that lasts anywhere from 6-24 hours. Adhesion molecules such as ICAM1 and ICAM3 are critical molecules generated by the T-cell during either phase and can bind to the adhesion molecules of DCs particularly DC-SIGN which is a known target of dengue. These molecules are necessary to form a stable synapse between the DC and T-cell[23]. T-cells, in turn, promote further maturation with the expression of CD40L. Further stimulation by cytokines such as TNF $\alpha$, IFN $\gamma$, IL-6, and others can rapidly promote the maturation and sensitivity of dendritic cells. In contrast, simulation of dendritic cells with IL-10 and other anti-inflammatory cytokines promotes a regulatory phenotype for DCs[24]. Regulatory dendritic cells have been shown to attenuate the immune response and promote tolerance in a way analogous to Tregulatory cells. DCs can also activate B-cells through costimulation of CD40, IL-6, and IL-12. The crux of DC interaction is in two places: DC maturation and T-cell synapse. Either point represents a potential target for dengue virus immune evasion. Should DCs fail to mature properly, they will not only fail to stimulate T-cells but they may induce tolerance. The DC-T-cell interaction is highly coordinated and disruption of the DC-T-cell synapse could promote dengue pathogenesis. Dengue-specific memory T-cells undergo simultaneous proliferation and apoptosis during a heterotypic infection. The end result is a less efficient and less specific T-cell response. The mechanism for this is unknown but given the intimacy between DCs and T-cells this represents a potentially productive field of research.

\section{The role of $\mathbf{T}$ cells in a dengue infection}

There is a clear consensus in the literature about activation of cross-reactive memory T-cells, independent of antibody enhancement, being a pivotal moment in the disease process. As compelling as ADE may be, it can not fully describe a complete picture of dengue pathogenesis such as, intense cytokine storm[25], tissue re-modeling[26], and effector cell activation[27]. The misregulation of Tcells centers around the idea of Original Antigenic Sin, or that a secondary heterotypic dengue infection can stimulate cross-reacting, low affinity T-cells. Activation of effector T-cells and secretion of cytokines define a key development in course of disease associated with dengue virus infection. Four patient studies done in Vietnam[28], India[29], Cuba[30], and Brazil[31] all showed increases in INF $\gamma$, TNF $\alpha$, IL-10, IL-1, IL-6, IL-8, and MCP1 amongst a variety of other cytokines. In vitro studies, IFN $\gamma$, IL-6, TNF $\alpha$, and RANTES upregulation also have been posited as important events in dengue pathogenesis[32]. A review of dengue-associated cytokines listed 15 different cytokines modulated by the disease. In short, these cytokines are consistent with widespread T-cell involvement. In particular IFN and TNF $\alpha$ were strongly associated with disease severity and correlate well with T-cell activation. In addition to increases in cytokine levels cellular markers for T-cell activation, CD69, CD38, and CCR7 have been shown to be increased in dengue infection[33] and IFN $\gamma$ secretion by dengue specific T-cells has been shown to upregulate the number of Fcy receptors. These receptors also play a noted role in Antibody dependant enhancement[34].

CD8+ cells have been shown to be important in helping control early viral infection; [35] but, the intense proliferation of CD8+ cells can also be implicated in dengue pathogenesis[36]. In tetramer staining, peripheral T-cells are collected from DHF patients and stained with an MHC tetramer complexed with a dengue-specific peptide. Tetramer positive T-cells can then be isolated and examined. When the tetramer positive cells were stained with Ki67, they show definitive proliferation. The cells are also found to be 'massively' apoptotic as determined by TUNEL staining. The balance of apoptotic cells with proliferative cells may skew $\mathrm{T}$ cell responses toward a crossreactive phenotype. When looking at the specific T-cells involved in secondary infections with DENV1, many of the T-cells show a preference for DENV3 tetramers and infections with DENV2 show preferences in T-cells for DENV1 and 3. Clearly, viruses are able to stimulate a variety of cross-reactive T-cell responses. Memory T-cells have a lower activation threshold than do naïve T-cells [37] and the low affinity non-neutralizing cells are potentially less efficient in clearing the virus[38]. Using a similar approach in a patient currently infected with DENV1 and a previous infection of DENV2, scientists find that $21 \%$ of 
the T-cell population reacted preferentially to DENV2 and $11 \%$ were specific for DENV1[39]. Sixty-eight percent of the T-cells in that study were fully cross-reactive between DENV2 and DENV1. When these cells are stimulated with DENV1 derived peptides, $51 \%$ of the cells specific for DENV2 responded with either granulation or cytokine release (TNF $\alpha /$ IFN $\gamma$ ) and $75-80 \%$ of the cross reactive and DENV1 specific T-cells responded to DENV1 epitopes. The role for the $49 \%$ of cells that demonstrate low affinity for DENV1 and do not respond to peptide stimulation is currently unknown, though their proliferation is certainly suggestive. When scientists infect immune competent mice with low dose heterologus dengue viruses they find enhanced CD8+ T-cell responses that were dependent on sequential viral infection as opposed to antibody enhancement. Enhanced cell mediated immunity likely causes target cell lysis through Perforin while bystander cell death is mediated through Fas ligand binding[40].

There is a differential cytokine secretion in response to antigen exposure in CD4+ cells in Dengue infected donors. The highest IFN $\gamma$ response was seen when cells were exposed homologous antigen. The cross-reaction IFN $\gamma$ response could potential confer limited protection, however, when cells were exposed to heterologus antigens they produced significantly higher amounts of TNF $\alpha$ in relation to IFN $\gamma[41]$. During primary infections in mice, dengue specific CD4+ cells were low; however, in all four viral serotypes of a secondary infection there is a marked increase CD4+ response. Not only did CD4+ cells increase IFN $\gamma$ production, but they increased CD8+ effector cell activation[42].

\section{Autoimmune disorder}

In addition to the antibody enhancement and T-cell disruption, autoimmune disorders are also important to dengue pathogenesis. Anti-NS1 antibody responses in mice have been shown to be cross-reactive in a variety of tissues. When human anti-NS1 antibodies were developed they showed affinity for human fibrinogen, thrombocytes, and endothelial cells[43]. NS1 is a glycoprotein that is secreted by infected cells, heavily present in patient serum supernatants, lacks a membrane spanning motif, but is not, itself, present in the virus. NS1 is known to be a major immune target and high concentrations of antiNS1 antibodies have been found in severe disease in patient studies[44]. When cells are exposed to NS1 antibodies they undergo intrinsic apoptosis, characterized by DNA fragmentation and phosphatidylserine exposure. Bcl-2 and Bcl-x decreased and P53, Bax, and cytochrome C increased in an iNOS dependent fashion. Apoptosis in response to Anti-NS1 antibody treatment can be blocked with an iNOS inhibitor[45]. The antibody mimicry is intensely inflammatory with anti-NS1 antibodies stimulating the release of IL-6, IL-8, and MCP-1 in an NFкB- dependent manner. Correlated with antibody binding is the upregulation of ICAM1. ICAM1 upregulation can facilitate the adherence of PBMCs to the endothelium. Both NFKB inhibitors and soluble NS1 to block the antiNS1 antibodies can able to block cytokine release in vitro[46]. Using ELISA flow cytometry, it can be shown that NS1 binds to the surface of uninfected cells. NS1binding motifs are commonly found in heparan sulfate and chondroitin sulfate E. In mouse experiments, tissues with a preponderance of these proteins are especially susceptible to this interaction and NS1 can be found bound to cells in the lung and liver but not intestine or brain endothelium of mouse tissues[47]. There is a high correlation between NS1 concentration in patient sera and high concentrations of anaphylatoxins which suggests a role for NS1 in complement activation. Further, anaphylatoxins are co-localized to the lungs and plasma in dengue infections. Co-localization experiments with membrane bound NS1 and NS1 specific antibodies showed the formation of complement attack complexes. Fluid phase NS1 can independently activate complement. Supernatants collected from dengue infected cells and mixed with normal sera shows complement activation by NS1 in a dose dependent manner[48]. When Dengue infected supernatants are mixed with purified antibodies from the sera from convalescent patients infected with dengue, complement activation is greatly enhanced. When they added purified NS1 protein to normal or convalescent sera they found synonymous results with NS1 activating complement and complement activation being synergized by anti-dengue antibodies. While NS1 could clearly activate complement in the fluid phase it was unable activate complement when stably expressed on the surface of cells. However, when patient samples were analyzed the found a strong correlation between NS1 concentration and C5b-C9 complex formation.

\section{Complement activated by dengue protein and antibodies}

The complement pathway is an ancient defense mechanism designed to serve both in a sentinel capacity and in effector function. There are three pathways to complement activation. The classical pathway begins with the formation of an antibody C1q complex on the surface of a pathogen or pathogen infected cell. This complex, in turn, activates $\mathrm{C} 2$ via serine proteases and is itself also a serine protease[49]. The protein C2a combines with newly cleaved protein $\mathrm{C} 4 \mathrm{a}$ to generate a $\mathrm{C} 3$ convertase, $\mathrm{C} 2 \mathrm{aC} 4 \mathrm{~b}$. $\mathrm{C} 3 \mathrm{~b}$ forms the central protein complex of the complement system either by binding to complement receptors or by complexing with $\mathrm{C} 2 \mathrm{aC} 4 \mathrm{~b}$ to form $\mathrm{C} 5$ convertase, $\mathrm{C} 2 \mathrm{aC} 4 \mathrm{bC} 3 \mathrm{~b}$. This complex can bind and stabilize C5a that forms the central effector function of the complement system around which proteins C5-C9 will bind and cooperatively lyse the cell. The mannose binding pathway has 
a similar cascade as the classical pathway but functions independently of antibody formation. Instead, MASP1 and MASP2 bind to mannose binds to the mannose structures commonly found on pathogens. The Mannan-binding lectin complex is closely homologous to $\mathrm{C} 1 \mathrm{q}$ and can activate $\mathrm{C} 2$ and $\mathrm{C} 4[50]$. In the absence of sialic acid sugars present on normal somatic cells and which are rare on pathogens, C1q begins a lytic cascade. There is a third pathway for complement activation that begins with spontaneous activation of complement proteins. In this pathway the thioester bonds in C3 undergo hydrolysis which allows the binding of Factor $\mathrm{B}$ and its subsequent cleavage by plasma protease Factor D. C3b and Factor Bb combine to form a C5 convertase. Runaway complement activation is prevented by binding of Complement Receptor 1 (CR1) and a constitutively active membrane bound Decay Accelerating Factor (DAF, or CD55) which can prevent the complement cascade[51]. In patients with severe dengue, large amounts of $\mathrm{C} 3 \mathrm{a}$ have been detected revealing a role for complement in dengue pathogenesis. This finding might be anticipated by the immune complexes that are the putative mechanism for dengue hemorrhage and shock syndromes. C3a finds some measure of importance by being one of several anaphylatoxins produced by complement activation capable of disrupting vasculature. C3a serves to recruit monocytes, macrophages, and dendritic cells, regulates vasodilatation, and increases permeability of small blood vessels and smooth muscle contraction. In macrophages, eosinophiles, and neutrophils anaphylatoxins can induce oxidative burst, basophiles, and mast cells release histamine, and C3a can enhance the effect of other proinflammatory cytokines such as TNF $\alpha$, IL-6, and SDF-1. While the mechanism for the many reactions precipitated by complement anaphylatoxins has not been fully elucidated, activation of $\mathrm{C} 3 \mathrm{aR}$ promotes cytokine expression through AKT phosphorylation as well as MAP kinase activation. C3aR is expressed on key mediators of the immune system like neutrophils, basophiles, eosinophiles, mast cells, monocytes/macrophages, dendritic cells, microglia, as well as, non myeloid cells like astrocytes, epithelial cells, smooth muscles cells, and activated T-cells, but, interestingly, not naïve T-cells. C5aR also activates a number of downstream signaling pathways including PI3K- $\gamma$ (Phosophoinosital -3 Kinase), PLC (Phospholipase C), PLD (Phospholipase D), Raf and WASP (Wiskott-Aldrich syndrome protein). As a key modulator of the immune system, complement derived proteins clearly have the capacity to affect an extraordinarily large number of cell types and tissues.

\section{Anaphylatoxins}

While TNF secretion and immune cell recruitment might be appropriately devastating, the effects of anaphylatoxins (AT) can be equally profound. C3a and C5a regulate vasodilatation, increase permeability of blood vessels, and can trigger degranulation and oxidative burst from neutrophils, eosinophiles, and basophiles. C3a and C5a act on specific receptors to produce local inflammatory responses and when secreted in concentrations high enough to invoke a general systemic response, they cause circulatory collapse similar to an IgE mediated allergic response. ATs modulate the secretion of IL-6, and TNF $\alpha$ from B cells and serve as potent chemoattractants[52]. C5a also works directly on neutrophils and monocytes to increase adhesion molecules, migration, and phagocytosis. Some of the primary sources of C3 are APCs such as dendritic cells and macrophages. Following antigenic stimulation both DCs and T-cells upregulate C3a and C5a receptors, produce $\mathrm{C} 3$, alternative complement factors $\mathrm{B}$ and $\mathrm{D}$, and downregulate CD55. Reduced CD55 promotes T-cell proliferation and Th1 cytokine expression. In addition to $\mathrm{C} 3$ production, APCs cleave C3 leading to autocrine and paracrine $\mathrm{C} 3 \mathrm{R}$ signaling. C3R signaling promotes MHC class II expression, IL-12 production and B7 co-stimulatory molecules. Dendritic cells that fail to express C3aR suffer reduced T-cell activation. Anaphylatoxins are well known initiators of inflammation but their role in regulating APC-T cell interactions is becoming increasingly prominent as more information is published. The crux of dengue pathogenesis lies in misregulation of immune processes and complement is sitting, figuratively, at the center of multiple key pathways. Anaphylatoxins become activated by DC antigen uptake and presentation. Cross reactive antibodies activate complement still further. The increase in alternative complement proteins, complement receptors and $\mathrm{C}$ protein all facilitate a positive feedback loop that can have dangerous consequences in a dengue infected patient.

\section{Conclusion}

Three immune components interact to produce a confluence of symptoms that define DHF/DSS. Dengue virus initially infects immature dendritic cells through the mediation of DC-SIGN. Infected dendritic cells contribute to pathogenesis through production of metalloproteases and cytokines. Downstream of dendritic cells T-cells become activated and generate the very cytokines implicated in vascular leak and shock in addition to activating effector cells. Antibody enhancement is mediated by Fc receptors which are prominently on mature dendritic cells. Viral replication mediated by antibodies is enhanced 100 -fold. In addition their effects on dengue replication, antibodies to viral epitopes cross react with cell a protein which has the effect of stimulating CD8 effector cells and production of cytokines and anaphylatoxins. Anaphylatoxins can be generated directly through viral proteins or through formation of an antibody-complement complex. Anaphylatoxins in turn can alter the reactivity of T-cells. Each year 50 million people will acquire dengue fever; 2.5 
billion people are at risk. There are few components of the immune that are unaffected by the virus. There are yet questions unanswered and the virus continues to spread unabated. However these immune components are several key elements attractive targets for study that hopefully can advance the field of research.

\section{Competing interests}

The author declares that they have no competing interests.

\section{Authors' informations}

David Gentry Nielsen was born 27, September 1982 in Reno Nevada. Shortly afterwards he and his family relocated to Brewster Washington. David attended Andrews University where he majored in Biology with a molecular emphasis and minored in Chemistry. He joined the department of Biomedical Sciences in the Tulane School of Medicine in 2005. During the "Hurricane Semester" he accepted a gracious invitation to the University of Washington in order to continue his studies while New Orleans recovered and returned to Tulane in 2006. He completed his Master's degree with this thesis in 2009.

\section{Acknowledgements}

I would like to acknowledge Dr. Robert Garry, Dr. Cindy Morris, Dr. Tom Voss, Dr. Deborah Sullivan, and Dr. Wimley for their personal and scientific contributions to this project. Their knowledge and expertise in were critical for its completion.

\section{References}

I. Impact of Dengue: World Health Organization. [http:// www.who.int/csr/disease/dengue/impact/en/index.html].

2. Dengue, Dengue haemorrhagic fever and Dengue shock syndrome in the context of the Integrated Management of Childhood IIIness [http://www.who.int/child adolescent health/ documents/fch cah 05 /3/en/index.html]

3. Dengue fever - eMedicine Emergency Medicine [http://emed icine.medscape.com/article/78|96I-overview]

4. Dengue DHS/DSS [http://www.whoindia.org/cds/DiseaseSurveil lance/IDSP/WHO\%20 Manual/vol2/DENGUE.pdf]

5. Mathew A, Rothman A: "Understanding the contribution of cellular immunity to dengue disease pathogensis". Immunoulogical Reviews 2008, 225:300-313.

6. Halstead S: "Neutralization and Antibody-Dependent Enhancement of Dengue Viruses". Advances in Virus Research 2003, 60:42I-467.

7. Goncalvez A, Engle R, St. Claire M, Purcell R, Lai C: "Monoclonal antibody-mediated enhancement of Dengue virus infection in vitro and in vivo and strategies for prevention". Proceedings of the National Academy of Sciences in the United States of America 2007, 104(22): $9422-9427$.

8. Goncalvez A, Engle R, St Claire M, Purcell R, Lai C: "Monoclonal antibody-mediated enhancement of Dengue virus infection in vitro and in vivo and strategies for prevention". Proceedings from the National Academy of Science USA 2007, 104:9422-9427.

9. Halstead S: "Dengue". Lancet 2007, 370:1644-52.

10. Halstead SB, Lan NT, Myint TT, Shwe TN, Nisalak A, Kalyanarooj S, Nimmannitya S, Soegijanto S, Vaughn DW, Endy TP: Dengue hemorrhagic fever in infants: research opportunities ignored. Emerging Infectious Disease 2002, 8: $1474-1479$.

II. can der Schaar H, Wilschut J, Smit J: "Role of antibodies in controlling dengue virus infection". Immunobiology 2009, 214:613-626.
12. Pierson TC, Xu Q, Nelson S, Oliphant T, Nybakken GE, Fremont DH, Diamond MS: "The stoichiometry of antibody-mediated neutralization and enhancement of West Nile virus infection". Cell Host Microbe 2007, I: I35- I 45.

13. Tirado SM, Yoon KJ: "Antibody-Dependent Enhancement of Virus Infection and Disease". Viral Immunology 2003, 16(I):69-86.

14. Cardosa MJ, Porterfield JS, Gordon S: "Complement receptor mediates enhanced flavivirus replication in macrophages". Journal of Experimental Medicine 1983, 158(I):258-63.

15. Janeway C, Travers P, Walport M, Shloochik M: Immunobiology :9-19 [http://www.ncbi.nlm.nih.gov/books/bv.fcgi?high light=Fc\&rid=imm.section. 1233\#1 234].

16. Goncalvez A, Engle R, St Claire M, Purcell R, Lai C: "Monoclonal antibody-mediated enhancement of Dengue virus infection in vitro and in vivo and strategies for prevention". Proceedings from the National Academy of Sciences United States of America 2007, 104(229422-9427 pnas.0703498104].

[http://www.pnas.org/cgi/doi//0.1073/

17. Pokidysheva E, Zhang Y, Battisti AJ, Bator-Kelly CM, Chipman PR, Xiao C, Gregorio GG, Hendrickson WA, Kuhn RJ, Rossmann MG: "Cryo-EM reconstruction of Dengue virus in complex with the carbohydrate recognition domain of DC-SIGN". Cell 2006, I 24:485-493.

18. Lozach PY, Burleigh L, Staropoli I, Navarro-Sanchez E, Harriague J, Virelizier JL, Rey FA, Desprès $P$, Arenzana-Seisdedos F, Amara A: "Dendritic cell-specific intercellular adhesion molecule 3grabbing nonintegrin (DC-SIGN)-mediated enhancement of Dengue virus infection is independent of DC-SIGN internalization signals". Journal Biological Chemistry 2005, 280:23698-23708.

19. Green S, Rothman A: "Immunopathological mechanisms in Dengue and Dengue hemorrhagic fever". Current Opinion in Infectious Disease 2006, 19(5):429-36.

20. boonnak K, Slike B, Burgess T, Mason R, Wu S, Sun P, Porter K, Rudinaman I, Yuwono D, Puthavathana P, Marovich M: "Role of Dendritic Cells in Antibody Dependent Enhancement of Dengue Virus Infection. Journal of Virology 2008:3939-395I.

21. Luplerdlop N, Misse D, Bray D, Deleuze V, Gonzalez JP, Leardkamolkarn $\mathrm{V}$, Yssel $\mathrm{H}$, Veas $\mathrm{F}$ : "Dengue virus infected dendritic cells trigger vascular leakage through metalloproteinase over production". EMBO Reports 2006, 7: II 76-I I8I.

22. Henrickson SE, Mempel TR, Mazo IB, Liu B, Artyomov MN, Zheng H, Peixoto A, Flynn MP, Senman B, Junt T, Wong HC, Chakraborty AK, von Andrian UH: "T cell sensing of antigen dose governs interactive behavior with dendritic cells and sets a threshold for T cell activation". Nature Immunology 2008, 9(3):282-91.

23. Bousso P: "T-cell activation by dendritic cells in the lymph node: lessons from the movies". Nature Review 2008, 8:675-684.

24. Palmer D, Sun P, Celluzzi C, Bisbing J, Pang S, Sun W, Marovich M, Burgess T: "Differential Effects of Dengue Virus on Infected and Bystander Dendritic Cells". Journal of Virology 2005:2432-2439.

25. Clark I: "The Advent of the Cytokine Storm". Immunology and Cell Biology 2007, 85:27I-273.

26. Luplertlop N, Missé D, Bray D, Deleuze V, Gonzalez JP, Leardkamolkarn V, Yssel H, Veas F: "Dengue Virus infected Dendritic cells trigger vascular leagage through metalloproteinase overproduction". EMBO Reports 2006, 7(II): I I76-II8I.

27. Green $S$, Rothman A: "Immunological mechanism in Dengue and Dengue hemorrhagic fever". Current Opinion in Infectious Diseases 2006, 19:429-436.

28. Nguyen TH, Nguyen TL, Lei HY, Lin YS, Le BL, Huang KJ, Lin CF, Do QH, Vu TQ, Lam TM, Yeh TM, Huang JH, Liu CC, Halstead SB: "Association Between Sex, Nutritional Status, Severity Of Dengue Hemorrhagic Fever, And Immune Status In Infants With Dengue Hemorrhagic Fever". American Journal of Tropical Medicine and Hygiene 2005, 72(4):370-374.

29. Chakravarti A, Kumaria R: "Circulating levels of tumour necrosis factor-alpha \& interferon-gamma in patients with Dengue \& Dengue haemorrhagic fever during an outbreak". Indian Journal Medical Research 2006, I 23(1): I I-4.

30. Pérez AB, García G, Sierra B, Alvarez M, Vázquez S, Cabrera MV, Rodríguez R, Rosario D, Martínez E, Denny T, Guzmán MG: "IL-IO levels in Dengue patients: Some findings from the exceptional epidemiological conditions in Cuba". Journal of Medical Virology 2004, 73(2):230-4. 
31. Bozza FA, Cruz OG, Zagne SM, Azeredo EL, Nogueira RM, Assis EF, Bozza PT, Kubelka CF: "Multiplex cytokine profile from Dengue patients: MIP-I beta and IFN-gamma as predictive factors for severity.". BMC Infectious Disease 2008, 8:86.

32. Lin YL, Liu CC, Chuang JI, Lei HY, Yeh TM, Lin YS, Huang YH, Liu HS "Involvement of Oxidative Stress, NF-IL-6, and RANTES Expression in Dengue-2-Virus-Infected Human Liver Cells". Virology 2008, 276(1): I14-126.

33. Mathew A, Rothman A: "Understanding the contribution of cellular immunity to Dengue disease pathogenesis". Immunological Reviews 2008, 225:300-3।3.

34. Kontny U, Kurane I, Ennis FA: "Gamma interferon augments Fcy receptor-mediated Dengue virus infection of human monocytic cells". Journal of Virology 1988, 62:3928-3933.

35. Yauch LE, Zellweger RM, Kotturi MF, Qutubuddin A, Sidney J, Peters B, Prestwood TR, Sette A, Shresta S: "A protective role for Dengue virus-specific CD8+ T cells". Journal of Immunology 2009 182(8):4865-73.

36. Rothman AL: "Immunology and immunopathogenesis of Dengue disease". Advanced Virus Research 2003, 60:397-4I9.

37. Veiga-Fernandes $H$, Walter $U$, Bourgeois C, McLean A, Rocha B: "Response of Naïve and memory CD8+ $T$ cells to antigen stimulation in vivo". Nature Immunology 2003, I:47-53.

38. Alexander-Miller M, Leggat G, Berzofsky J: "Selective expansion of High or Low avidity Cytotoxic T lymphocytes and efficacy for adoptive immunotherapy". Proceedings of the National Academy of Science United States of America 1996, 93:4102-4I07.

39. Mongkolsapaya J, Duangchinda T, Dejnirattisai W, Vasanawathana S, Avirutnan $P$, Jairungsri A, Khemnu N, Tangthawornchaikul N, Chotiyarnwong P, Sae-Jang K, Koch M, Jones Y, McMichael A, Xu X, Malasit $P$, Screaton G: "T cell responses in Dengue hemorrhagic fever: are cross-reactive T cells suboptimal?". Journal of Immunology 2006, I76(6):382I-9.

40. Gagnon S, Ennis F, Rothman A: "Bystander Target Cell Lysis and Cytokine Production by Dengue Virus-Specific Human Cd4+ Cytotoxic T-Lymphocyte Clones". Journal of Virology 1999, 73(5):3623-3629.

41. Mangada M, Rothman A: "Altered Cytokine Responses of Dengue-Specific CD4+ T cells to heterologous Serotypes". The Journal of Immunology 2005, I 75:2676-2683.

42. Beaumier C, Rothman A: "Cross-Reactive Memory CD4+ T cells Alter the CD8+ T cell response to Heterologous Secondary Dengue Virus Infections in Mice in a Sequence Specific Manner". Viral Immunology 2009, 22(3):215-219.

43. Falconar AK: "The Dengue virus nonstructural-I protein (NSI) generates antibodies to common epitopes on human blood clotting, integrin/adhesin proteins and binds to human endothelial cells: potential implications in haemorrhagic fever pathogenesis". Archives of Virology 1997, 142(5):897-916.

44. Monath TP, Heinz FX: Flaviviruses. In Fields virology Volume I. Edited by: Fields BN, Knipe DM, Howley PM, Chanock RM, Melnick JL, Monath TP, Roizman B. Lippincott-Raven, Philadelphia; 1995:96I-1034.

45. Lin CF, Lei HY, Shiau AL, Liu HS, Yeh TM, Chen SH, Liu CC, Chiu SC, Lin YS: "Endothelial cell apoptosis induced by antibodies against Dengue virus nonstructural protein I via production of nitric oxide". Journal of Immunology 2002, 169(2):657-64.

46. Lin CF, Chiu SC, Hsiao YL, Wan SW, Lei HY, Shiau AL, Liu HS, Yeh TM, Chen SH, Liu CC, Lin YS: "Expression of cytokine, chemokine, and adhesion molecules during endothelial cell activation induced by antibodies against Dengue virus nonstructural protein I". Journal of Immunology 2005, 1 74(I):395-403.

47. Avirutnan P, Zhang L, Punyadee N, Manuyakorn A, Puttikhunt C, Kasinrerk W, Malasit P, Atkinson JP, Diamond MS: "Secreted NSI of Dengue virus attaches to the surface of cells via interactions with heparan sulfate and chondroitin sulfate E". PLoS Pathogens 2007, 3(I I): el 83.

48. Avirutnan P, Punyadee N, Noisakran S, Komoltri C, Thiemmeca S, Auethavornanan K, Jairungsri A, Kanlaya R, Tangthawornchaikul N, Puttikhunt C, Pattanakitsakul SN, Yenchitsomanus PT, Mongkolsapaya J, Kasinrerk W, Sittisombut N, Husmann M, Blettner M, Vasanawathana S, Bhakdi S, Malasit P: "Vascular Leakage in Severe Dengue Virus Infections: A Potential Role for the nonstructural Viral Protein NSI and Complement". Journal of infectious Disease 2006, 193(8): 1078-88.
49. Basta M: "Ambivalent effect of immunoglobulins on the complement system: activation versus inhibition". Molecular Immunology 2008, 45:4073-4079.

50. Janeway C, Travers P, Walport M, Shlomchick M: Immunobiology Section 2: the complement system and innate immunity. [http://www.ncbi.nlm.nih.gov/bookshelf/ br.fcgi?book=imm\&part=AI48\#AI6I].

51. Harboe M, Mollnes TE: "The alternative complement pathway revisited". Journal of Cellular and Molecular Medicine 2008, I 2(4): 1074-1084.

52. Klos A, Tenner AJ, Johswich KO, Ager RR, Reis ES, Köhl J: "The role of the anaphylatoxins in health and disease". Molecular Immunology 2009, 46(I4):2753-66.
Publish with Bio Med Central and every scientist can read your work free of charge

"BioMed Central will be the most significant development for disseminating the results of biomedical research in our lifetime. "

Sir Paul Nurse, Cancer Research UK

Your research papers will be:

- available free of charge to the entire biomedical community

- peer reviewed and published immediately upon acceptance

- cited in PubMed and archived on PubMed Central

- yours - you keep the copyright

Submit your manuscript here:

http://www.biomedcentral.com/info/publishing_adv.asp
BioMedcentral 